Research Article

\title{
Effect of Notch on Strain Rate Concentration Factor of 304 Stainless Steel Bar
}

\author{
Zhengyang Yu, ${ }^{1}$ Bin Zhong $\mathbb{D}^{1},{ }^{1}$ Yaojie Sun, ${ }^{2}$ and Lei $\mathrm{Ma}^{2}$ \\ ${ }^{1}$ School of Mechanical Engineering, Xi'an University of Science and Technology, No. 58 Yanta Middle Road, Xi'an, China \\ ${ }^{2}$ Institute for Electric Light Sources, Engineering Research Center of Advanced Lighting Technology, Ministry of Education, \\ Fudan University, Shanghai, China
}

Correspondence should be addressed to Bin Zhong; zhongbin2015@xust.edu.cn

Received 16 September 2020; Revised 25 January 2021; Accepted 8 February 2021; Published 3 March 2021

Academic Editor: José António Fonseca de Oliveira Correia

Copyright (c) 2021 Zhengyang Yu et al. This is an open access article distributed under the Creative Commons Attribution License, which permits unrestricted use, distribution, and reproduction in any medium, provided the original work is properly cited.

\begin{abstract}
In this study, the notch effect of different types of 304 stainless steel rod notch is studied because of the problem of difficulty in measuring the notch root strain of 304 rod stainless steel, and the parameters of the annular notch root are analyzed. The notch angle, notch depth, and notch root radius are the main parameters of the stress field affecting the annular notch, and the mathematical expression of the strain rate concentration factor is derived. In order to verify the accuracy of the theory, the mechanical model of 304 stainless steel bar is established by finite element and numerical simulation calculation. The results show that the theoretical and finite elements have a high degree of agreement. When the notch angle increases, both theoretical and finite elements show a downward trend. When the notch depth of 304 stainless steel bar increases, both theoretical and numerical simulations show an increasing trend. The notch root radius of 304 stainless steel bar increases with decreasing numerical simulation.
\end{abstract}

\section{Introdution}

304 stainless steel is widely used in industrial application because of its good mechanical properties and corrosion resistance $[1,2]$. For example, metal chains, bearings, and various bearing parts, and all shaft-related parts are processed using metal bar material cropping $[3,4]$. The quality cross section directly affects the machining quality and production efficiency of the subsequent parts. To obtain better section quality, reasonable notch parameters are needed.

Geometric discontinuity can produce stress concentration $[5,6]$ or strain concentration phenomenon locally, and this geometric discontinuity can be regarded as a notch. Stress concentration or strain concentration at the notch can constrain the yield and plastic deformation of the material, resulting in notch strengthening and embrittlement of the material $[7,8]$. The notch produces stress concentration at its root due to strain concentration. Then, the application of external load is reduced. At present, Zhao [9] et al. performed the analysis of different notch shapes based on the notch root stress field and found that the symmetric V-type notch is more suitable for the notch shape in industrial production. Tamate and Shioya [10] and Neuber [11] use the theory of stress concentration factor to study the double notches and the single notch and find that the stress concentration factor of the double notches and the single notch are basically the same. Meanwhile, Nao-Aki et al. [12] find that the stress concentration factors of the single edge notch and those of the double edge notches are in close agreement except for the case of the deep notch in the transverse bending problem of the strip. Nao-Aki and Takase [13]. conducted a study stress concentration coefficient based on different notch root radii. It is found that the stress concentration coefficient increases with the decrease of notch root radius. Moreover, Nao-Aki et al. [14-16] studied different notch geometries (notch depth and notch angle), temperature, ratio of notch parameters (notch root radius to bar diameter ratio, notch depth to bar net section radius, notch) The distance ratio between depth and notch axis and notch edge, the minimum section diameter of rod material, and the maximum section diameter ratio are studied in 
depth. However, Nao-Aki et al. calculated the strain rate concentration factor mainly by the stress concentration factor and studied the strain rate concentration factor through statics and geometry without considering the internal relationship between stress and strain. To sum up, the strain rate concentration factor is rarely used to analyze the notch effect because the measurement of notch root strain is very difficult.

In this paper, the strain rate concentration factor was defined as the ratio of the strain rate in notched specimen to the strain rate in smooth specimen. The strain rate concentration factor is used to study the notch effect of different types of notch, and the proposed strain rate concentration factor theory is verified by numerical simulation. The use of appropriate notch can reduce the external load and energy consumption.

\section{Definition of the Strain Rate Concentration Factor}

In this paper, 304 stainless steel is selected as the test material. The chemical composition of 304 stainless steel is shown in Table 1. The material properties are shown in Table 2 .

The metal bar specimen is often used for metal testing as shown in Figure 1. By considering the tensile test method for metallic materials, the specimen length $l=70 \mathrm{~mm}$ and the maximum specimen diameter $D=10 \mathrm{~mm}$ are considered. In this work, the notch opening angle is $\theta=90^{\circ}$ and notch root radius is $R=0.2 \mathrm{~mm}$.

Assume notch root radius $R=0.2 \mathrm{~mm}, R=0.15 \mathrm{~mm}$, and $R=0.1 \mathrm{~mm}$, while the notch depth is $b=0.5 \mathrm{~mm}, b=1 \mathrm{~mm}$, and $b=1.5 \mathrm{~mm}$. Figure 1 (a) shows the finite element model
TABle 1: 304 main chemical composition of stainless steel (percentage by weight).

\begin{tabular}{lccccccc}
\hline $\mathrm{C}$ & $\mathrm{P}$ & $\mathrm{Mn}$ & $\mathrm{Si}$ & $\mathrm{S}$ & $\mathrm{Cr}$ & $\mathrm{Ni}$ & $\mathrm{Fe}$ \\
\hline 0.045 & 0.030 & 0.71 & 0.81 & 0.028 & 17.16 & 8.15 & Margin \\
\hline
\end{tabular}

TABLE 2: Mechanical properties of 304 stainless steel.

\begin{tabular}{lccccc}
\hline Material & $\sigma_{\mathrm{b}} / \mathrm{MPa}$ & $\psi / \%$ & $\varepsilon_{\mathrm{f}}$ & $E / \mathrm{GPa}$ & $\sigma_{\mathrm{f}} / \mathrm{MPa}$ \\
\hline 304 stainless steel & 494 & 32.4 & 0.392 & 192 & 654 \\
\hline
\end{tabular}

for analysis in notch root radius $R=0.2 \mathrm{~mm}$, while Figure 1(b) shows the notch specimen.

When the metal bar is in a plane strain state, the strain field at the notch root is expressed as follows:

$$
\varepsilon=\varepsilon_{2}-u\left(\varepsilon_{1}+\varepsilon_{3}\right),
$$

where $u$ is Poisson's ratio.

As shown in Figure 2, finite element analysis is carried out for different types of notches.

The strain rates in notch and smooth specimens are $\dot{\varepsilon}_{\text {notch }}$ and $\dot{\varepsilon}_{\text {smooth }}$. The strain rate in smooth specimen is expressed as follows [14]:

$$
\dot{\varepsilon}_{\text {smooth }}=\frac{u(t) / L}{t},
$$

where $u(t) / t$ is the tensile rate and $L$ is the effective length of the tensile specimen.

The strain rate in the notch specimen evolved according to the definition of strain, and the strain rate in the notch specimen is as follows:

$$
\dot{\varepsilon}_{\text {notch }}=\frac{\varepsilon}{t}=\frac{\left(\int_{b_{1}}^{b_{2}} b-u\left(\int_{b_{1}}^{b_{2}} b \int_{\beta_{1}}^{\beta_{2}} \tan \theta+\int_{b_{1}}^{b_{2}} b \int_{\beta_{1}}^{\beta_{2}} 1 / \cos \beta\right)\right)}{(w-2 b) t}+\frac{\left(\int_{b_{1}}^{b_{2}} b-u\left(\int_{b_{1}}^{b_{2}} b \int_{\alpha_{1}}^{\alpha_{2}} \tan \alpha+\int_{b_{1}}^{b_{2}} b \int_{\alpha_{1}}^{\alpha_{2}} 1 / \cos \beta\right)\right)}{(w-2 b) t},
$$

where $b$ is the notch depth, $\beta$ and $\alpha$ are the angle between the notch axis and the notch edge, and wis relative specimen diameter.

The strain rate concentration factor is expressed as follows [16]:

$$
\dot{K}_{\varepsilon}=\frac{\dot{\varepsilon}_{\text {notch }}}{\dot{\varepsilon}_{\text {smooth }}} .
$$

\section{Effect of Notch Opening Angle}

3.1. Notch Opening Angle Analysis. Under the fixed specimen length $l=70 \mathrm{~mm}$, the maximum specimen diameter $D=10 \mathrm{~mm}$, the notch root radius $R=0.2 \mathrm{~mm}$, and the notch depth $b=1 \mathrm{~mm}$, the strain rate concentration factor is calculated by varying the specimen notch opening angle. The different types of notch opening angle angles are shown in
Table 3. Symmetric notch and asymmetric notch are shown in Figure 3.

By bringing the above specimen size data into formulas (1), (2), and (3), the strain rate concentration factor at different notch opening angles can be obtained as shown in Table 4.

3.2. Finite Element Simulation. Eight different types of notch modeling are first used in the analysis and calculation using ABAQUS software, then the model is meshed, and the same grid parameters are set to ensure the reliability of the analysis results. In addition, the loading conditions are set to the same, the six degrees of freedom of the metal bar are limited, and the same load is applied. Figure 4 shows the Mises stress figure after loading, and the maximum stress appears at the notch.

Table 4 and Figure 4 show the strain rate concentration factor and Mises stress figures for different notch opening 


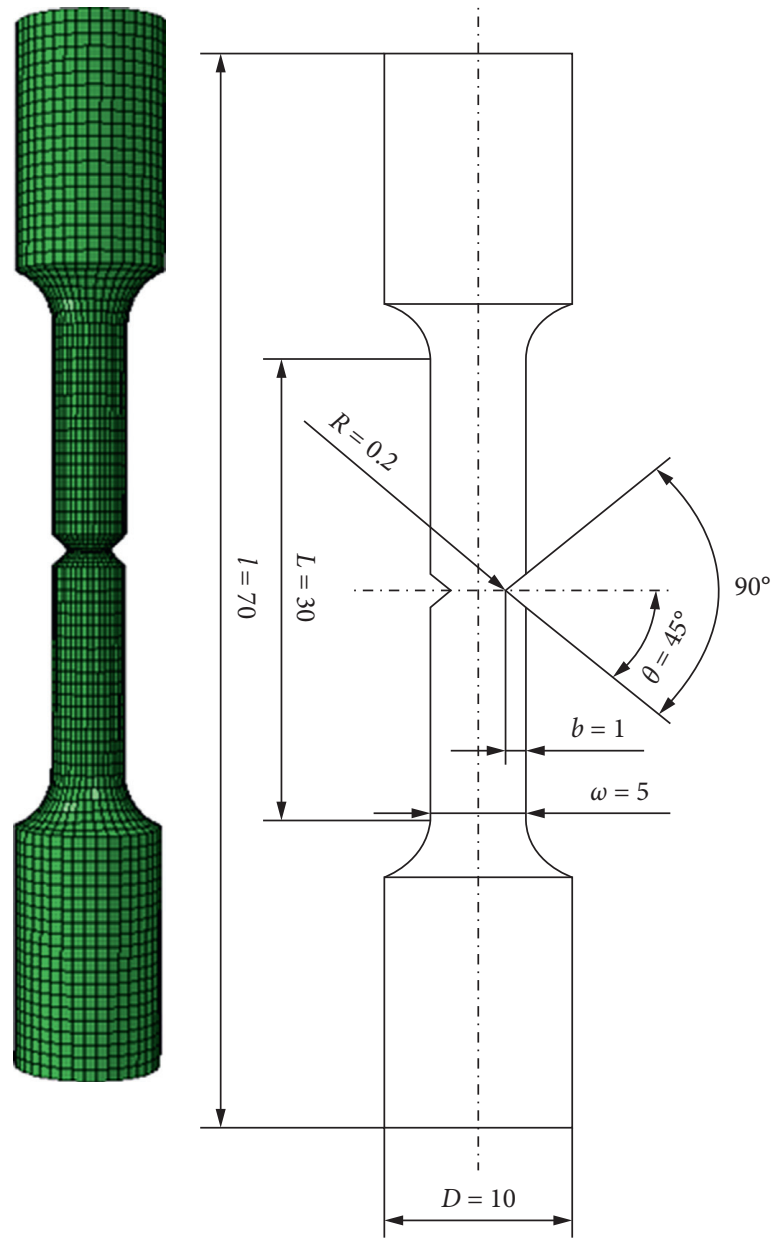

(a)

(b)

FIgURE 1: Geometry of (a) finite element model and (b) notch specimen.

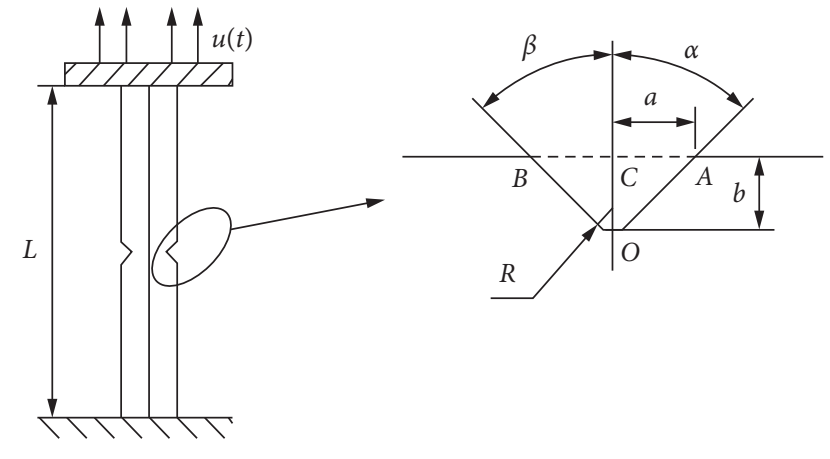

Figure 2: Tensile specimens.

angles. With increasing notch opening angle, the strain rate concentration factor and Mises stress figure decrease. $\mathrm{V}$ notch has greater stress concentration effect, which is caused by strain concentration effect.

\section{Effect of Notch Depth}

Under the fixed specimen length $l=70 \mathrm{~mm}$, the maximum specimen diameter $D=10 \mathrm{~mm}$, and the notch root radius
TABLE 3: The types of notch opening angle.

\begin{tabular}{lcc}
\hline Notch shape & Symmetric notch & Asymmetric notch \\
\hline \multirow{2}{*}{ Notch opening angle } & 30,45 & 30,45 \\
& $60, \mathrm{U}$ & $60, \mathrm{U}$ \\
\hline
\end{tabular}

$R=0.2 \mathrm{~mm}$, the strain rate concentration factor is calculated by varying the specimen notch depth. The types of notch depths are $0.5 \mathrm{~mm}, 1 \mathrm{~mm}$, and $1.5 \mathrm{~mm}$.

By bringing the above specimen size data into formulas (1), (2), and (3), the strain rate concentration factor at different notch depths can be obtained as shown in Table 5 .

Nine different types of notch modelings are first used in the analysis and calculation using ABAQUS software, then the model is meshed, and the same grid parameters are set to ensure the reliability of the analysis results. Figure 5 shows Mises stress figure after loading. Furthermore, Section 2 has completed the simulation with a notch depth of $1 \mathrm{~mm}$.

Table 5 and Figure 5 show the strain rate concentration factor and Mises stress figures for different notch depths. With increasing notch depth, the strain rate concentration factor and Mises stress figure increase. 


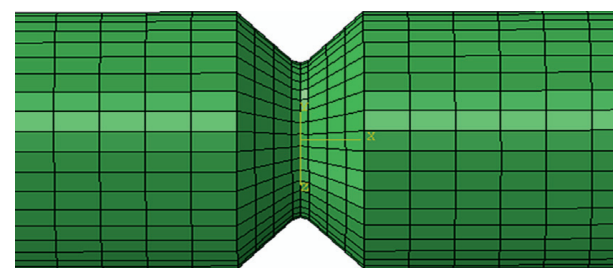

(a)

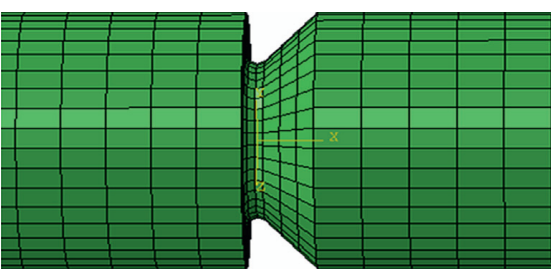

(b)

FIgUre 3: (a) Symmetric notch. (b) Asymmetric notch.

TABLE 4: Strain rate concentration factor at different notch opening angles.

\begin{tabular}{ccccccc}
\hline & Symmetric 30 & Symmetric 45 & Symmetric 60 & Asymmetric 30 & Asymmetric 45 & Asymmetric 60 \\
\hline $\mathrm{t} \mathrm{K}$ & 1.056 & 0.842 & 0.529 & 0.528 & 0.421 & 0.265 \\
\hline
\end{tabular}

$\mathrm{S}$, mises (avg: 75\%)

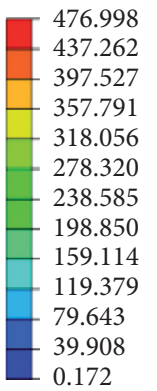

0.172

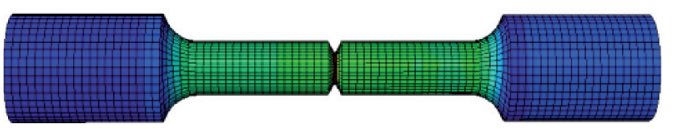

(a)

$\mathrm{S}$, mises (avg: 75\%)

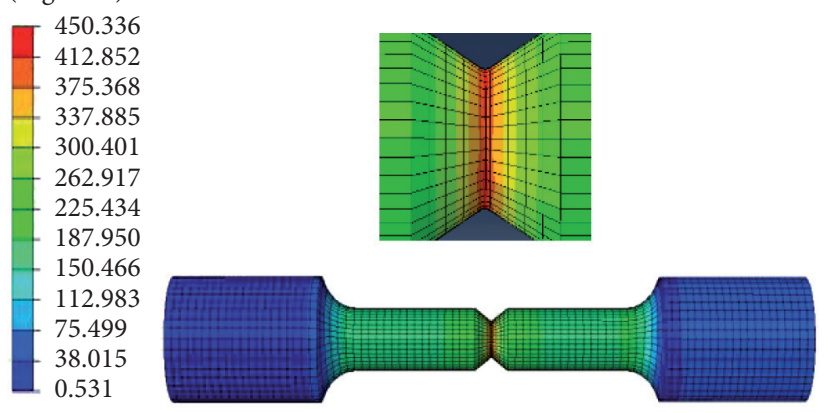

(c)

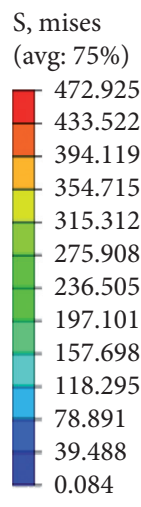

$\mathrm{S}$, mises (avg: 75\%)
472.925
433.522
394.119
315.312
75.908
157.698
18.295
39.488
0.084

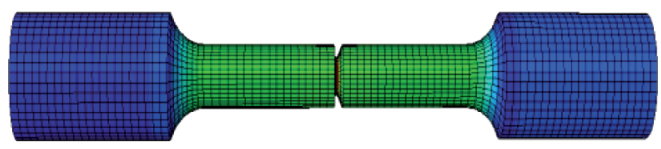

(e)

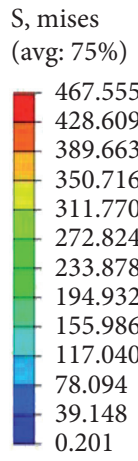

$\mathrm{S}$, mises

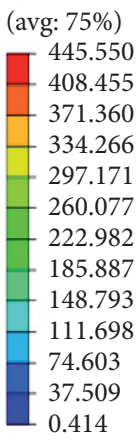

(b)
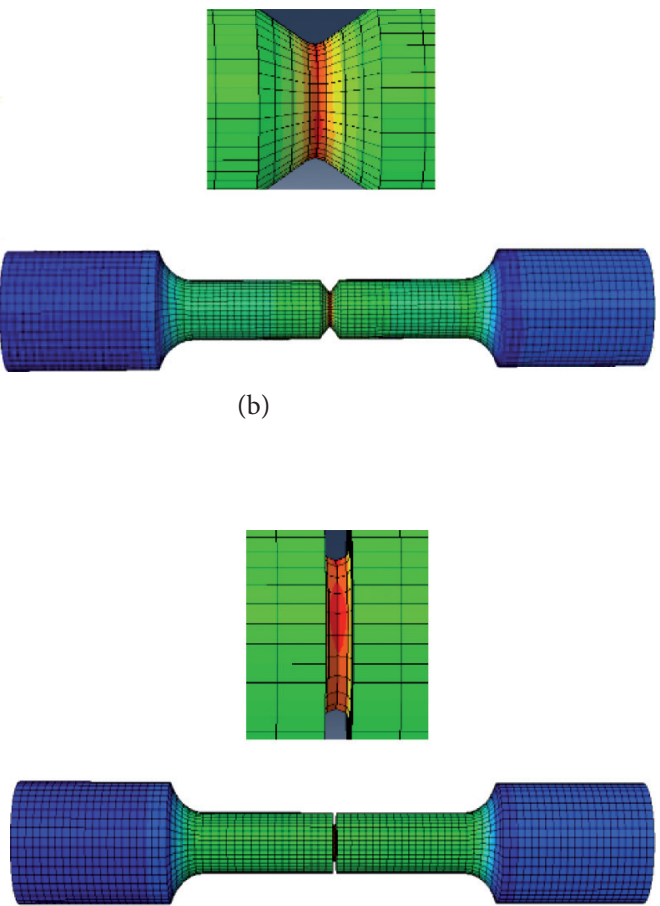

(d)

$\mathrm{S}$, mises (avg: 75\%)
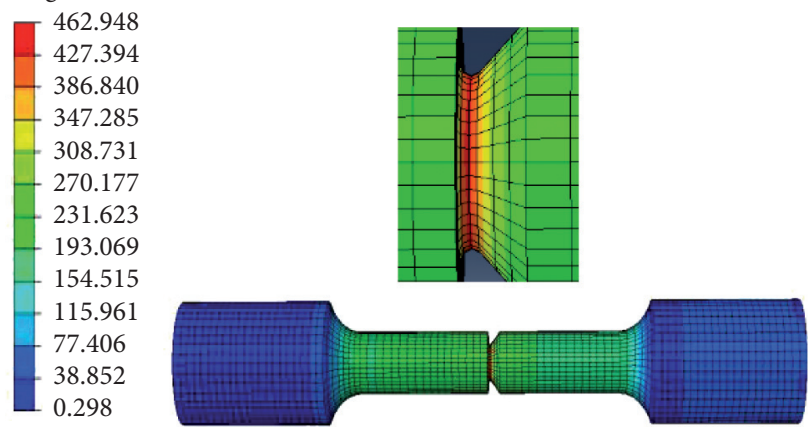

(f)

Figure 4: Continued. 


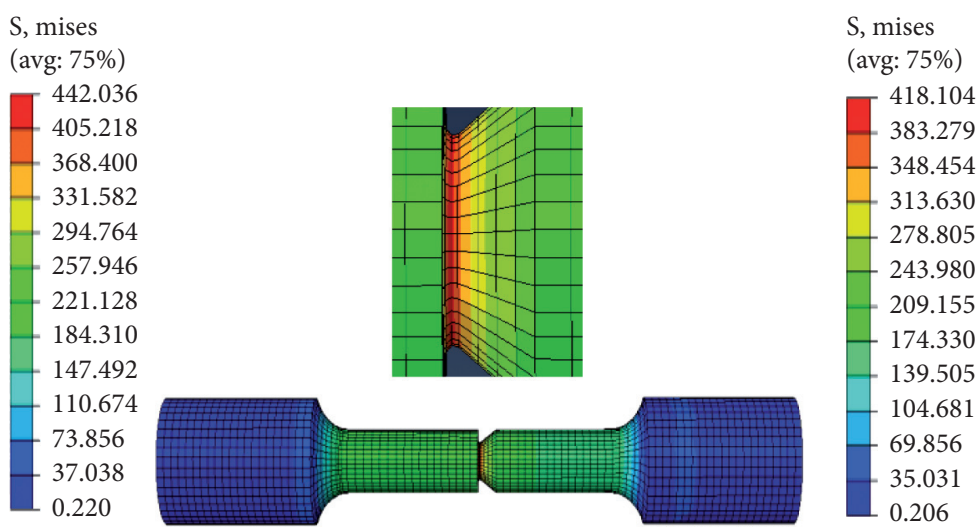

(g)

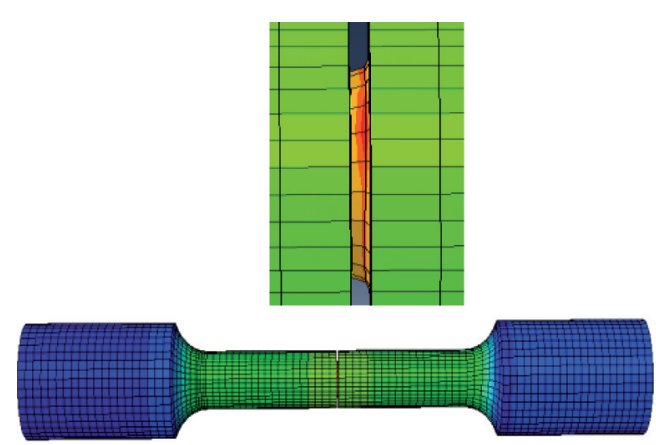

(h)

Figure 4: Mises stress figures of different notch opening angles: (a) symmetric 30, (b) symmetric 45, (c) symmetric 60, (d) symmetric U, (e) asymmetric 30, (f) asymmetric 45, (g) asymmetric 60, and (h) asymmetric $\mathrm{U}$.

TABLE 5: Strain rate concentration factor at different notch depths.

\begin{tabular}{lccc}
\hline & & & \\
$\theta$ & & $\dot{K}_{\mathrm{t} \varepsilon}$ & $b$ \\
& $0.5 \mathrm{~mm}$ & $1 \mathrm{~mm}$ & $1.5 \mathrm{~mm}$ \\
\hline Symmetric 30 & 0.446 & 1.056 & 2.079 \\
Symmetric 45 & 0.355 & 0.842 & 1.658 \\
Symmetric 60 & 0.223 & 0.529 & 1.042 \\
\hline
\end{tabular}

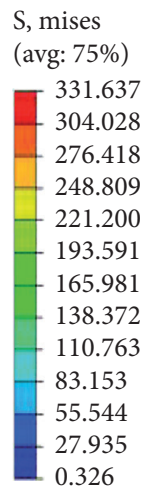

S, mises (avg: 75\%)

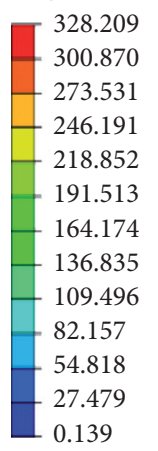

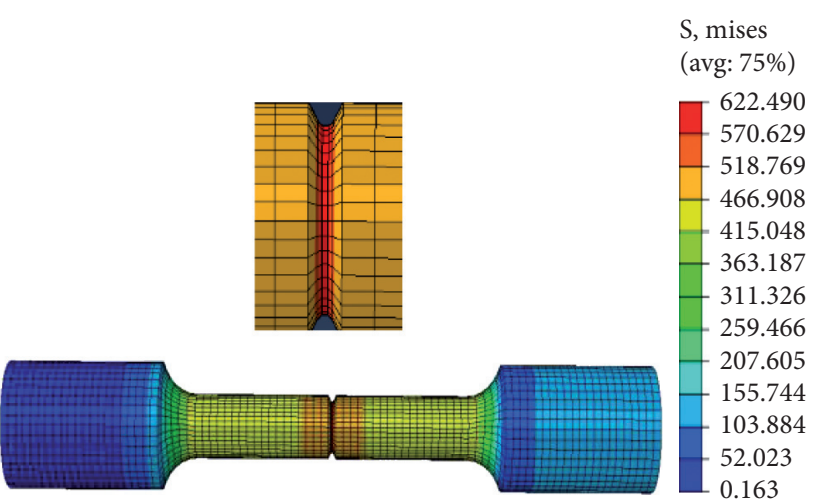

(A)

(a)

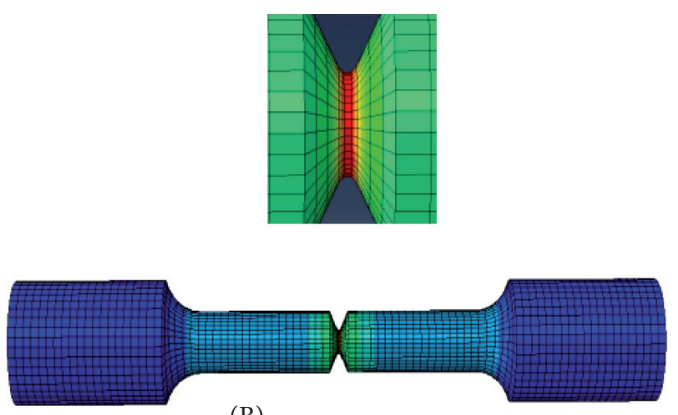

(B)

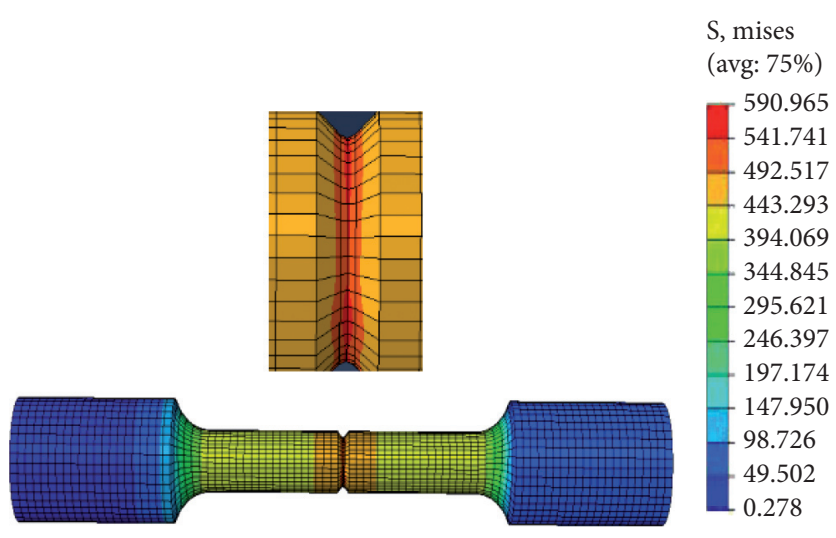

(A)

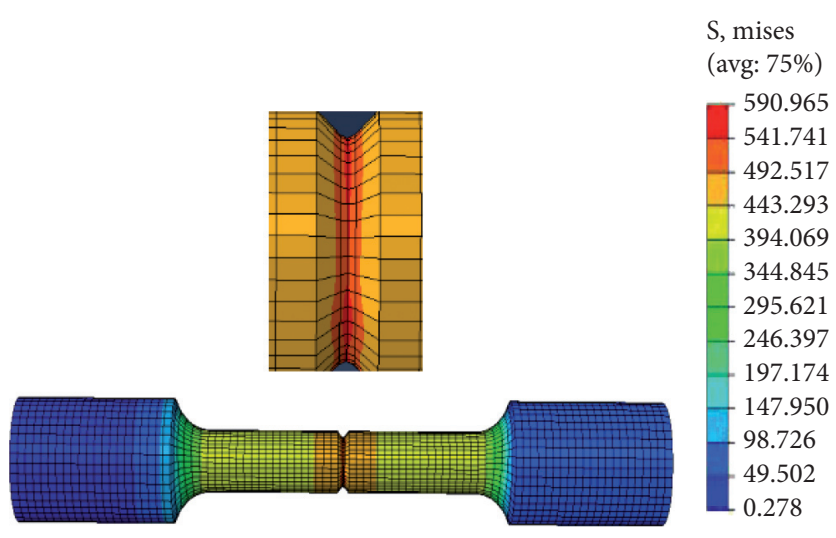

(b)

Figure 5: Continued. 


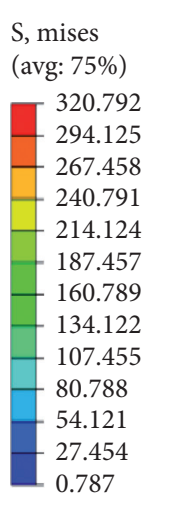

(avg: $75 \%$ )

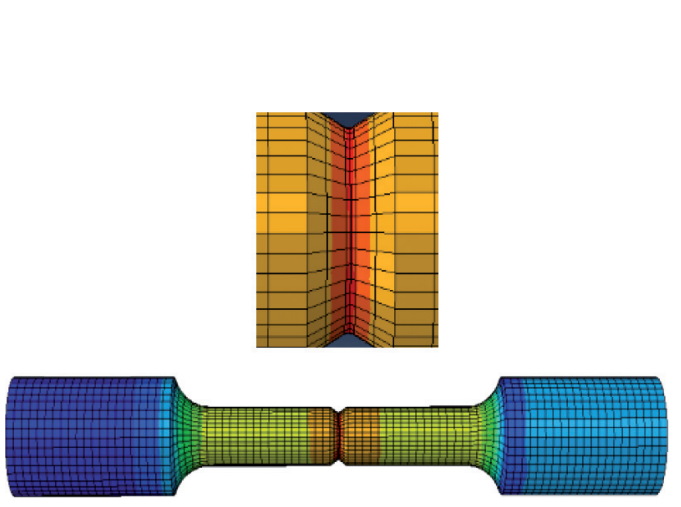

(A)

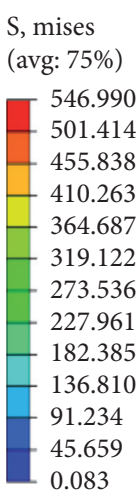

(c)

Figure 5: Mises stress figures of different notch depths. (a) Symmetric 30: notch depth of (A) $0.5 \mathrm{~mm}$ and (B) $1.5 \mathrm{~mm}$. (b) Symmetric 45: notch depth of (A) $0.5 \mathrm{~mm}$ and (B) $1.5 \mathrm{~mm}$. (c) Symmetric 60: notch depth of (A) $0.5 \mathrm{~mm}$ and (B) $1.5 \mathrm{~mm}$.

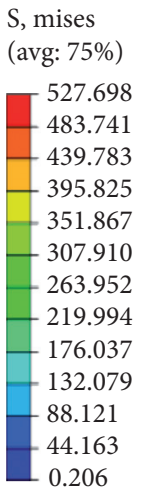

S, mises

(avg: $75 \%$ )

504.283
-462.264
-420.245
-378.226
-336.208
-294.189
-252.170
-210.151
-168.133
-126.114
-84.095
42.076

0.057

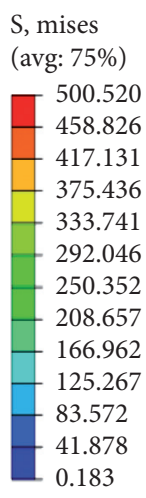

(A)

(a)

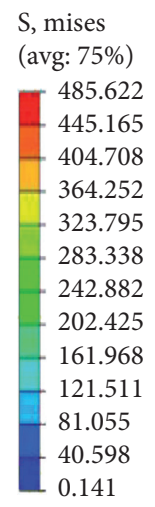

(A)
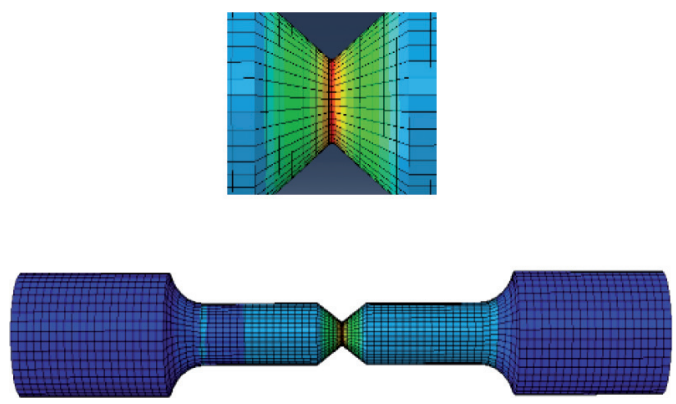

(B)
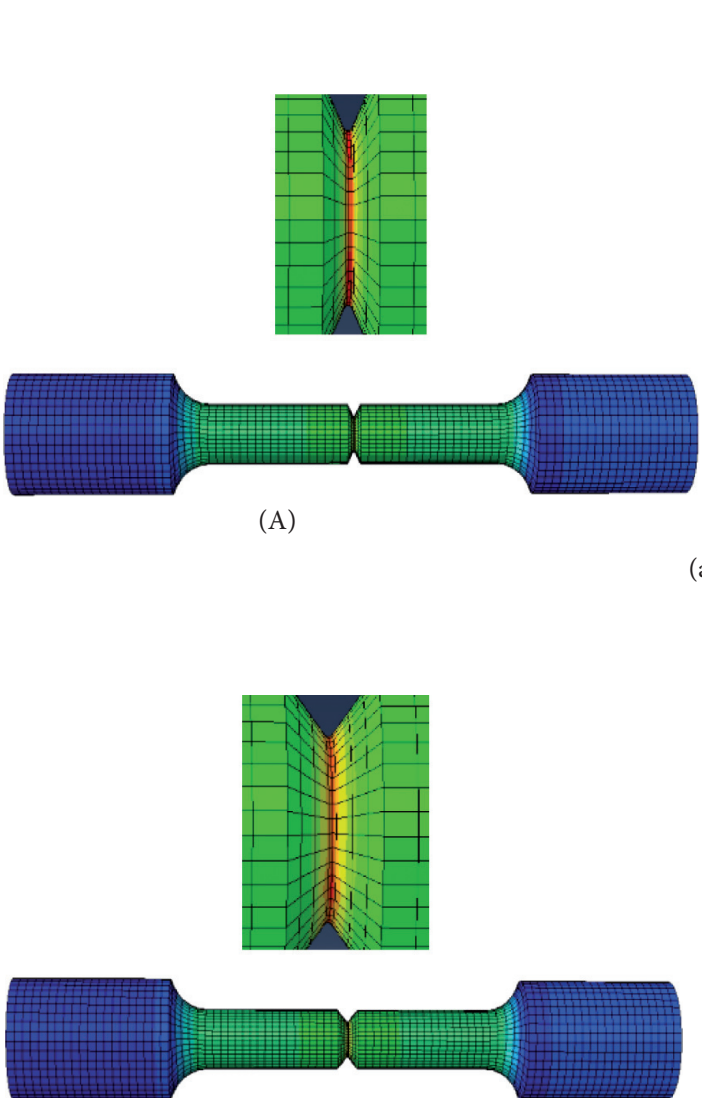

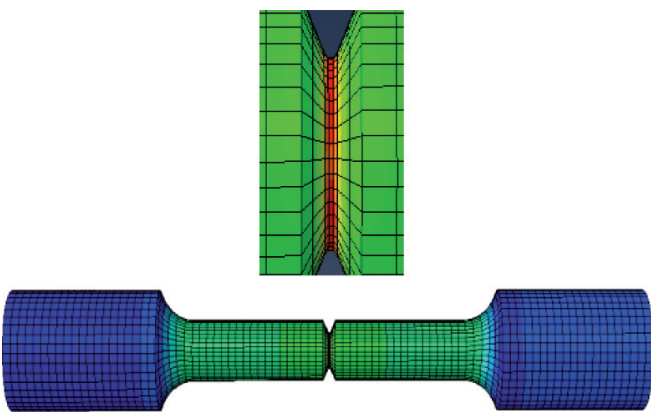

(B)

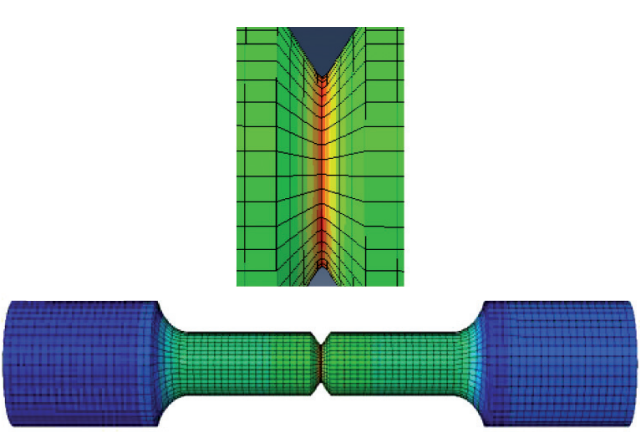

(B)

(b)

Figure 6: Continued. 

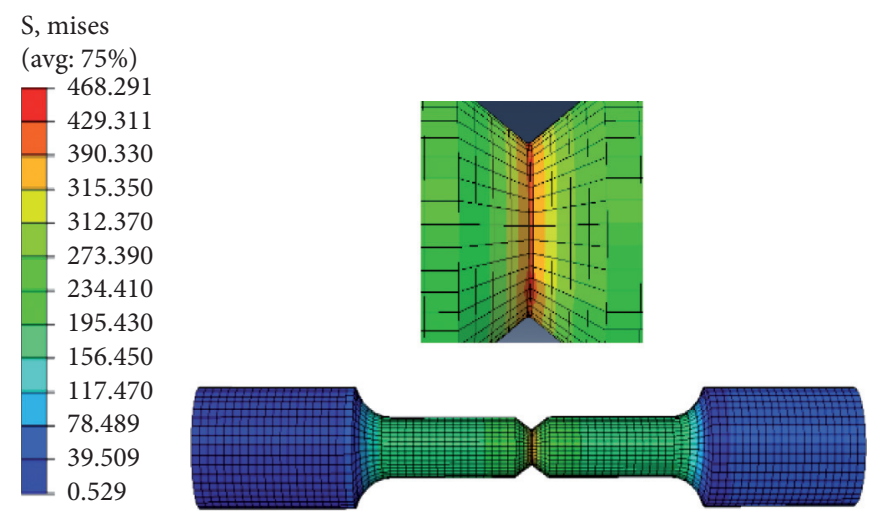

(A)

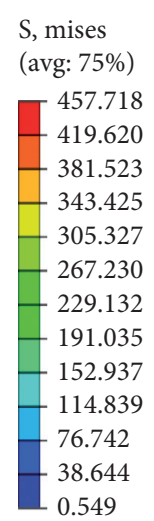

(c)

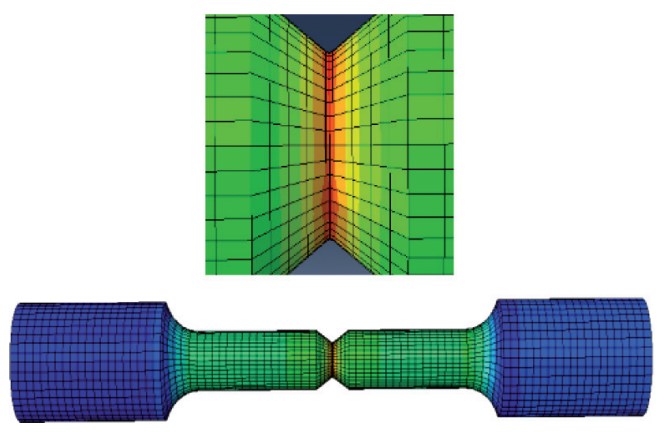

(B)

Figure 6: Mises stress figures of different notch root radii. (a) Symmetric 30: notch root radius (A) $0.1 \mathrm{~mm}$ and (B) $0.15 \mathrm{~mm}$. (b) Symmetric 45: notch root radius (A) $0.1 \mathrm{~mm}$ and (B) $0.15 \mathrm{~mm}$. (c) Symmetric 60: notch root radius (A) $0.1 \mathrm{~mm}$ and (B) $0.15 \mathrm{~mm}$.

\section{Effect of Notch Root Radius}

Under the fixed specimen length $l=70 \mathrm{~mm}$, the maximum specimen diameter $D=10 \mathrm{~mm}$, and the notch depth $b=1 \mathrm{~mm}$, the strain rate concentration factor is calculated by varying the specimen notch root radius. The types of notch root radius are $0.1 \mathrm{~mm}, 0.15 \mathrm{~mm}$, and $0.2 \mathrm{~mm}$.

Nine different types of notch modelings are first used in the analysis and calculation using ABAQUS software, then the model is meshed, and the same grid parameters are set to ensure the reliability of the analysis results. Figure 6 shows the stress cloud after loading. Furthermore, Section 2 has completed the simulation with a notch root radius of $0.2 \mathrm{~mm}$.

Figure 6 shows Mises stress figures for different notch root radii. With increasing notch root radius, Mises stress figure and stress concentration decrease.

\section{Conclusion}

The strain rate concentration factor is used in this work. Both theoretical calculation and the corresponding finite element are carried out to investigate the notch effect. After summarizing the results in tables and figures, the following conclusions are obtained:

(1) The strain rate concentration factor is defined as the ratio of the strain rate in notched specimen to the strain rate in smooth specimen.

(2) Similar to the stress concentration factor, the strain rate concentration factor decreases with the increase of notch opening angle. $V$ notch is more strain rate-concentrated than $U$ notch.

(3) The strain rate concentration factor increases with increasing notch depth, and stress concentration decreases with increasing notch root radius.

\footnotetext{
Abbreviations

l: $\quad$ Specimen length

D: $\quad$ Maximum specimen diameter
}

$\begin{array}{ll}\theta: & \text { Notch opening angle } \\ R: & \text { Notch root radius } \\ b: & \text { Notch depth } \\ u: & \text { Poisson's ratio } \\ u(t) / t: & \text { Tensile rate } \\ L: & \text { Effective length of specimen } \\ w: & \text { Relative specimen diameter } \\ K_{\mathrm{t} \varepsilon}: & \text { The strain rate concentration factor } \\ \dot{\mathcal{E}}_{\text {notch }}: & \text { Strain rate in notched specimen } \\ \mathcal{E}_{\text {smooth }}: & \text { Strain rate in smooth specimen } \\ \mathcal{\varepsilon}: & \text { Strain. }\end{array}$

\section{Data Availability}

304 stainless steel chemical composition and material mechanical data were used to support this study and are available at Zhenshi Group Eastern Special Steel Co., Ltd. The numerical simulation data of tensile test used to support the findings of this study are included in the article.

\section{Conflicts of Interest}

The authors declare no potential conflicts of interest with respect to the research, authorship, and/or publication of this article.

\section{Acknowledgments}

The authors gratefully acknowledge financial support from the National Natural Science Foundation of China (Grant no. 51705416).

\section{References}

[1] X. yang, M. Liu, Z. Liu, C. Du, and X. Li, "Failure analysis of a 304 stainless steel heat exchanger in liquid sulfur recovery units," Engineering Failure Analysis, vol. 116, Article ID 104729, 2020. 
[2] L. Gardner, "Stability and design of stainless steel structures-Review and outlook," Thin-Walled Structures, vol. 141, no. 141, pp. 208-216, 2019.

[3] Z. Yu, B. Zhong, C. Zhang et al., "Theoretical and experimental study on optimal cropping load control strategy of duralumin alloy $\mathrm{AlCu} 4 \mathrm{Mg} 1$ based on linear elastic fracture mechanics," Proceedings of the Institution of Mechanical Engineers Part C-Journal of Mechanical Engineering Science, vol. 234, no. 238, pp. 1630-1639, 2020.

[4] C. J. Hua, S. D. Zhao, L. J. Zhang, and W. Liu, "Investigation of a new-type precision cropping system with variable-frequency vibration," International Journal of Mechanical Sciences, vol. 48, no. 12, pp. 1333-1340, 2006.

[5] C. Shin, K. Man, and C. Wang, "A practical method to estimate the stress concentration of notches," International Journal of Fatigue, vol. 16, no. 4, pp. 242-256, 1994.

[6] A. R. Torabi and M. R. Jafarinezhad, "Comprehensive data for rapid calculation of notch stress intensity factors in U-notched Brazilian disc specimen under tensile-shear loading," Materials Science and Engineering: A, vol. 541, pp. 135-142, 2012.

[7] N. Troyani, S. I. Hernandez, and G. Villarroel, "Theoretical stress concentration factors for short flat bars with opposite U-shaped notches subjected to in-plane bending," International Journal of Fatigue, vol. 26, no. 12, pp. 1303-1310, 2004.

[8] R. Afshar and F. Berto, "Stress concentration factors of periodic notches determined from the strain energy density," Theoretical and Applied Fracture Mechanics, vol. 56, no. 3, pp. 127-139, 2011.

[9] R. Zhao, J. Zheng, Q. Wang et al., "Influence of different type notches on micro cracks initiation in the tubes precision blanking process," Journal of Plastivity Engneering, vol. 25, pp. 276-282, 2018.

[10] O. Tamate and S. Shioya, "On the transverse flexure of an infinite strip with semicircular notches on both edges," Transactions of the Japan Society of Mechanical Engineers, vol. 24, no. 147, pp. 809-818, 1958.

[11] H. Neuber, Kerbspannungslehre, Springer, Berlin, Germany, 2nd edition, 1958.

[12] N. Nao-Aki, T. Masa-Aki, and N. Hironobu, "Stress concentration of a strip with $\mathrm{V}$ - or U-shaped notches under transverse bending," Engineering Fracture Mechanics, vol. 31, no. 1, pp. 119-133, 1988.

[13] N. Nao-Aki and Y. Takase, "Stress concentration formula useful for all notch shape in a round bar (comparsion between torsion, tension and bending)," International Journal of Fatigue, vol. 28, pp. 151-163, 2006.

[14] N. Nao-Aki, R. Takaki, Y. Shen et al., "Strain rate concentration factor for flat notched specimen to predict impact strength for polymeric materials," Mechanics of Materials, vol. 131, pp. 141-157, 2019.

[15] N. Nao-Aki, H. Ohtsuka, H. Zheng et al., "Strain rate concentration and dynamic stress concentration for double-edge-notched specimens subjected to high-speed tensile loads," Fatigue \& Fracture of Engineering Materials \& Structures, vol. 38, pp. 125-138, 2015.

[16] N. Nao-Aki, Y. Shen, R. Takaki et al., "Relationship bewteen strain rate concentration factor and stress concentration factor," Theoretical and Applied Fracture Mechanics, vol. 90, pp. 218-227, 2017. 